British Journal of Education

Vol.8, Issue 2, pp.52-62, February 2020

Published by ECRTD- UK

Print ISSN: ISSN 2054-6351

Online ISSN: ISSN 2054-636X

\title{
THE EFFECT OF ACTIVE LEARNING STRATEGIES ON DEVELOPING SELF-EFFICACY AND ACADEMIC ACHIEVEMENT FOR SEVENTH GRADE STUDENTS IN JORDAN
}

\author{
Idgeish Ismail Idgeish Al- Mahaftha \\ Email: Idgheish@ yahoo.com phone number: 00962796174107 \\ Southern Ghour Post Office, Postal code: (61110)
}

\begin{abstract}
The study aimed to investigate the impact of active education strategies on developing self-efficacy academic achievement. The number of the study members reached (59) students from the seventh primary grade. They were chosen from the seventh primary grade students. To achieve the goals of the study, a measure was used in the subjective effectiveness, and an achievement test in the subject of Islamic education. The results of the study revealed the presence of statistically significant differences between the results of students in the two groups in the study of self-efficacy and academic achievement, in favor of the experimental group. This study concluded with a number of proposals calling for concern to employ active learning strategies in the various subjects.
\end{abstract}

KEYWORD: active learning, self-efficacy, academic achievement, students

\section{INTRODUCTION}

Self-organized learning is a new and important trend in the study of students' academic achievement, as it was previously viewed through its relationship to ability, the quality of teaching, or the family environment. On the contrary, the self-organized learning theory focuses its attention on answering the following question:

How can the learner observe and practice learning practices in specific situations? According to this approach, students with high mental ability are not achieving optimal achievements due to their failure to use or control both cognitive, emotional, or behavioural learning processes. Hence, the theories of self-organized learning focus their attention on questions such as: why and how learners control their learning (Purdie, Hattie \& Doug, 1996, p, 90; Zimmerman, 2002, p. 66).In addition, theories of learning self-systems assume that there is no environment that guarantees to learn, as good learning environments require changes in the choice and construction of attitudes for learning to occur (Zimmerman, 2002, p, 67).

Given this change in the interpretation of the learning process, the concept of the teaching process has changed on the one hand and the role of both the teacher and the learner on the other hand. After the education process focused on how to organize the stimuli in the 
British Journal of Education

Vol.8, Issue 2, pp.52-62, February 2020

Published by ECRTD- UK

Print ISSN: ISSN 2054-6351

Online ISSN: ISSN 2054-636X

external educational environment in a way that leads the learner gradually to the required responses, and then support it through immediate and intermittent reinforcement, this process has become concerned with creating educational situations and presenting them to the learner in the form of problems that require him to think about these situations and Use his cognitive processes to process, coordinate, organize, and classify the information it contains in meaningful cognitive patterns that lead to problem-solving. As for the learner's role in the educational learning process, after he was expected to perform individual responses that are rewarding, observable and measurable as a sign of learning, he has to become an active person in receiving structured information for her, and an employee of his mental capabilities and cognitive strategies to address it. Its coordination, classification, coding, assimilation, and analysis into meaningful cognitive patterns (Darwazeh, 2004, $\mathrm{p}, 38)$. Therefore, the educational learning process requires a fundamental change in the role of the teacher and entering the adventure of partnership with learning, a partnership that is not limited to the classroom but extends to the entire experience of the learner (Jurdak, 1997, p. 24).

Also, when we encourage students to participate in activities that lead them to discuss and ask questions and clarifications regarding the content of the subject, we not only work to preserve the best information for the subject but also help to develop their thinking capabilities (Myers \& Jones, 1993, p. .29). Some advocates of active learning add another importance, which is that the many activities on which this type of learning depends reduce negative learning activities such as passive listening, taking and taking notes throughout class time, in a manner that raises their motivation to learn and indulge in them (Carroll \& Leander, 2001, p33).

\section{The study Problem:}

In light of the massive information explosion that we observe these days, this requires the development of a method of learning encouraging students to take responsibility in dealing with this unlimited amount of knowledge, which is only successful with active learning, hence the importance of active learning and the need to train students to active learning and practice its strategies from Through programs prepared for that or through training within the content, and an appreciation by the researcher for the importance of training students on active learning strategies, the research problem was determined in investigating the impact of active learning strategies on developing self-efficacy for students of the seventh grade.

\section{Specifically, the current study attempted to answer the following two questions:}

1. What is the effect of the active learning strategy on developing self-efficacy for the seventh-grade students?

2. What is the effect of the active learning strategy on developing academic achievement for seventh-grade students?

From the previous two questions, two hypotheses emerged: 
British Journal of Education

Vol.8, Issue 2, pp.52-62, February 2020

Published by ECRTD- UK

Print ISSN: ISSN 2054-6351

Online ISSN: ISSN 2054-636X

1. There were no significant differences in the subjective effectiveness scale between the average performance of the experimental group that was exposed to the active learning strategy and the average performance of the control group in the post-test.

2. There are no significant differences in academic achievement in Islamic education between the average performance of the experimental group that was exposed to the active learning strategy and the average performance of the control group in the post-test.

\section{The importance of studying}

The importance of the current study emerges from the nature of the subject you are looking at, as the search for an effective method of teaching still occupies the minds of researchers. In solving problems related to the implementation of the curriculum, underachievement of students, and in solving other problems that may be encountered by the teacher. The importance of this study stems from a number of theoretical and practical justifications, where recent trends emphasize the role of the learner in the educational process after it is active, not independent, or passive recipient consuming knowledge, the stimulus is waiting until it responds, but it is an initiator and planner and collects educational activities (Wittrock, 1990, p,356).

\section{Procedural definitions}

Active learning: Any activity that the learner does in the classroom other than passive listening to what the teacher says inside the classroom so that it instead includes positive listening that helps them understand what they hear, writing the most important ideas contained in what is said, sayings, opinions or explanations, and comment Or comment on it, and deal with group exercises and activities in a way that applies what they have learned in different life situations, or solve various daily problems.

Self-efficacy: refers to the hypothetical beliefs that an individual possesses about his ability (Bandura, 1997, p. 54). And procedurally known as the degree obtained by the learner on the scale of academic self-efficacy used in this study.

Academic Achievement: It is the result of what a student learns after a period of study, and his ability to retrieve, understand and apply the learned content, measured by the score obtained by the student on an achievement test prepared by the researcher, and from a multiple-choice type that measures the results expected to be achieved in Islamic education.

\section{Previous studies}

McCarthy \& Anderson (2000) conducted a study aimed at investigating the impact of active learning with its various methods, including the method of collective role play and cooperative learning activities as effective methods for diversifying the educational activities of university students in history and political science courses, and investigating their impact on increasing the academic achievement of university students A comparison with regular teaching methods. The results of the study showed that students who learned 
British Journal of Education

Vol.8, Issue 2, pp.52-62, February 2020

Published by ECRTD- UK

Print ISSN: ISSN 2054-6351

Online ISSN: ISSN 2054-636X

using active learning methods scored better than their peers who learned using regular teaching methods in achievement tests and performance assessment tests.

Carroll \& Leander (2001) also conducted a study aimed at increasing the motivation of fifth-grade students to learn in the subject of social education through employing active learning strategies, as the two researchers used conceptual networks and various questions methods in order to improve students' higher thinking skills and increase their ability To organize and understand data and information, and collaborative learning in order to increase students' motivation and enhance their social communication skills. The class visits conducted by the two researchers also showed that the students' attitudes towards education were negative, and that the students were not interested in learning activities. The results of the study indicated a noticeable improvement in the students' motivation towards learning as a result of employing active learning strategies, as well as a marked increase in the level of academic achievement of students as a result of the improvement of their attitudes towards learning. The study also showed that active learning methods increased students' confidence in their ability to learn.

In a study by Wilke (2003), I aimed to investigate the effect of employing active learning strategies on academic achievement and stimulating motivation and self-efficacy for Angelo University students in the US state of Texas in the physiology course. The study sample included an experimental group that was taught the course by employing active learning strategies and a control group that was taught the same course by employing the usual teaching methods such as the lecture method. The results of the study showed that there were statistically significant differences in the motivation of the experimental and control groups, and that the students in the experimental and control groups had positive attitudes towards active learning, and they reported that active learning helps them learn university courses better than the traditional lecture method.

In a study by Taraban, R.; Box, C.. Myers, R.; Pollard, R. \& Bowen, C. (2007) aimed to investigate the effect of employing active learning strategies on academic achievement and student attitudes and behaviors in biology in a school High school in the state of Texas, and divided the students into two groups: a control group and an experimental group. All what was going on inside the classroom and two active learning labs was recorded to monitor teacher practices and teaching methods that he uses in teaching curriculum content and monitoring student behavior and attitudes. In the active learning lab they have gained a greater amount of comparative educational content Those who have learned in the regular classroom The study also confirmed that the active learning that takes place in the active learning laboratories and the curriculum that is designed to study by employing active learning strategies, wants the effectiveness of students inside the classroom, improves their attitudes towards learning, and promotes collaborative work between them, Enhance their self-learning and increase their understanding of the content of the subject. 
British Journal of Education

Vol.8, Issue 2, pp.52-62, February 2020

Published by ECRTD- UK

Print ISSN: ISSN 2054-6351

Online ISSN: ISSN 2054-636X

Tandogan, R. \& Orhan, A. (2007) conducted a study aimed at investigating the effect of employing a problem-solving method based on active learning strategies on the academic achievement of seventh-grade students in one of Istanbul's schools in Turkey in science and their understanding of concepts The study sample included two groups, one in control and the other is experimental The members of the control group were taught using traditional teaching methods while students of the experimental group were taught the same curriculum content using a problem-solving method based on active learning strategies The results of the study that were based on the achievement of the experimental and experimental groups was that the experimental group students 'results in the achievement test were much higher than their peers in the control group due to the teaching methods used. The study results also showed that employing a problem-solving method based on active learning strategies had a major impact in improving achievement level Students 'study and improving their attitudes toward science, the study also showed that employing active learning strategies contributed greatly to improving students' understanding of scientific concepts.

Scheyvens, R Griffin, A., J Ocoy, C., Liu, Y. \& Bradford, M. (2008) conducted a study aimed at investigating the effect of employing active learning strategies on geography teaching and the importance of these strategies in involving learners in the educational situation Compared to the usual teaching methods in which the teacher dominates the educational situation, and does not provide the opportunity for learners to actively participate in it. The study emphasizes the importance of employing active learning strategies in teaching geography and rejecting all beliefs that employing active learning strategies is difficult to implement in many educational situations because it requires that students have prior knowledge of the content of the educational situation and that applying the majority of active learning strategies requires an effort Great for teachers and students alike.

Through reviewing previous studies, it is clear that the need requires developing teaching methods in order to bring about development in student learning and achieving the goals that are focused on supporting and building scientific meanings. This study has come, which we hope will carry among its folds an achievement for teachers to effective learning procedures, and develop a model for the concept of teaching Oriented towards self-efficacy and raising the level of academic achievement through the use of active learning strategies.

\section{METHOD AND PROCEDURES}

The members of the study sample were chosen from the seventh-grade students from the Directorate of Education in the Southern Jordan Ghour for the year 2019/2020 AD.The number of the study sample population was 59 students who were distributed in two divisions representing the two study groups. The arithmetic mean for the marks of each 
division was approved in the first exam of Islamic education for the first semester of the year 2019/2020, which is held at the end of the first month. Table (1) shows these averages.

Table (1) Distribution of study sample individuals according to the number of students, mean, and standard deviations for students' marks in the first exam in Islamic education

\begin{tabular}{|l|l|l|l|}
\hline Classroom Division & N & mean & SD \\
\hline A & 29 & 15.4 & 2.36 \\
\hline B & 30 & 19.97 & 1.73 \\
\hline
\end{tabular}

To compare these divisions and ensure their averages are equal, (independent samples Ttest ) was used for, Table (2), where the apparent difference between these averages did not indicate any statistical significance.

Table (2) (T-test) results to indicate the differences in the averages of the two study groups on the first exam in the subject of Islamic education

\begin{tabular}{|l|l|l|l|}
\hline Group & $\mathrm{N}$ & $\mathrm{T}$ & sig \\
\cline { 1 - 2 } Experimental & 29 & -1.54 & 0.131 \\
\cline { 1 - 2 } Control & 30 & & \\
\hline
\end{tabular}

\section{Study procedures}

After applying the pre-test and self-efficacy scale on the two groups, the control group was taught in the lecture-style while the experimental group was taught using the method of asking questions, brainstorming, field visits and the project method of active learning strategies, which is the strategy adopted by this study, where the plans included a description of the method of teaching and learning, And also included guidelines, directions and discussion questions. When writing the educational material according to this strategy, he took into consideration the reorganization of the educational content for each topic in a manner consistent with the active learning strategy and specifying the previous requirements necessary for the new learning as it is presented in the introduction, providing feedback to students whenever necessary, as well as guiding them during the presentation of the educational material in Various missions. Then, the post-test and the self-efficacy scale were applied to the control and experimental groups after the experiment ended.

\section{Study tools:}

1. Self-efficacy scale: In this study, the self-efficacy scale developed by Ghanem (2007) was used in a doctoral thesis, and it consists of (30) paragraphs distributed in a quadruple Likert scale (applies to a large degree, applies to a medium degree, hesitant, does not apply to a large degree, Not fully applicable), and each of these categories is given the following scores respectively $(1,2,3,4,5)$, and the paragraphs on this scale are measured in two 
dimensions: general self-efficacy and special self-efficacy, a measure in which the psychometric properties required Such measures, his psychometric properties have been validated in the doctoral thesis, as repelling indicators were extracted Ge using two methods: apparent honesty (arbitrators), and discriminatory honesty, as indicators of reliability of the scale, were extracted using two methods: reliability in the way of return, as the reliability factor (0.85), and reliability in the way of internal consistency, as the total reliability factor (0.82). For further scrutiny, the scale was applied in the current study by the research team to an exploratory sample from the seventh-grade students, Fatima AlZahraa Primary School for Girls outside the study sample, the number of its members reached (20) students, and the reliability factor was found in the method of internal consistency, and the Cronbach factor reached Alpha (0.86), which is an appropriate value for the current study. Appendix 1 shows the self-efficacy scale used in the current study. To ensure that the two study groups are equal on the self-efficacy scale, the scale was applied before the study was carried out on two groups, and mathematical averages, standard deviations and (T-test) results were extracted to indicate the differences between the averages on the scale, and Table (3) shows these results.

Table (3) (T-test ) results to indicate differences in the averages of the two study groups on the self-efficacy scale

\begin{tabular}{|l|l|l|l|l|l|}
\hline Group & $\mathrm{N}$ & mean & SD & T & sig \\
\hline Experimental & 29 & 73.69 & 33.78 & 1.14 & 0.261 \\
\cline { 1 - 4 } Control & 30 & 66.10 & 11.95 & & \\
\hline
\end{tabular}

It is noted from Table No. (3) that there are no statistically significant differences at the level of significance $(\alpha \leq 0.05)$ on the tribal scale of self-efficacy, which means that the two groups are equivalent.

Academic achievement scale:

A test achievement in the Islamic education subject was used after the experiment to measure the effectiveness of strategies on academic achievement within the first three levels of Bloom's taxonomy (knowledge, understanding and application), and the formation of the test in its final form of 20 paragraphs of multiple-choice, where the number of alternatives (4) was alternatives for each paragraph The twenty paragraphs were distributed at the goal levels as follows: 6 paragraphs in the level of knowledge and remembering 10 paragraphs in the level of understanding and understanding, and 4 paragraphs in the level of application. As for the steps that were followed in building this test, they were represented as follows:

1- Determine the goals included in the aforementioned teaching plans, analyze the content, and prepare the specifications table based on determining the relative weight of the goals and content.

2- Formulating 20 paragraphs to be the primary test. 
3- Presenting the test in its initial form with its twentieth paragraphs and its specifications table in the form of arbitrators and asking them to arbitrate the test paragraphs in terms of the integrity of the paragraphs from a scientific and linguistic point of view, and the extent to which each paragraph relates to the level of its intended purpose, and to make any other observations that they see appropriate. And discuss their observations and suggestions, and in light of that, the paragraphs of the test were finalized, thus verifying the content of this test.

4- Calculating the reliability constant of the test by applying the test to a survey sample from the study community (outside the study sample) numbering (30) students (15 mail students, 15 female students), and then calculating the reliability factor using the (KR-20) equation and the consistency coefficient has reached The internal procedure is $(0.89)$, which is high and acceptable for the purposes of the current study. Factors of difficulty and discrimination of test items were also found. The difficulty coefficients ranged between (0.32 and 0.78), with the exception of one paragraph that was classified as difficult. Its difficulty was $(0.87)$, and the discrimination coefficients ranged between $(0.68-0.16)$.

\section{Study design}

Since this semi-empirical study tries to study the effect of active learning on developing self-efficacy and academic achievement, study variables can be categorized as follows:

1- The independent variable: it represents the teaching strategy and has two levels:

a. Active learning.

B. Regular teaching.

2- The dependent variables In the study, there are two dependent variables:

a. Self-efficacy.

B. Academic achievement.

Table (4) shows the semi-experimental design of the study and represents a predimensional design of asymmetric groups.

Table (4): the semi-experimental design approved in the study

\begin{tabular}{|l|l|l|l|l|}
\hline Experimental & Self-efficacy & Active learning & Self-efficacy \\
measure & $\begin{array}{l}\text { Regular } \\
\text { teaching }\end{array}$ & $\begin{array}{l}\text { Academic } \\
\text { Achievement } \\
\text { Scale }\end{array}$ \\
\hline
\end{tabular}

\section{Statistical processing}

To achieve the aims of the study and examine its hypotheses of measuring the effect of the teaching strategy on developing self-efficacy and academic achievement, test results (T) were used to reveal the significance of the differences between the average scores for students of the two groups on the scale of post-test of the self-efficacy and academic achievement. 
British Journal of Education

Vol.8, Issue 2, pp.52-62, February 2020

Published by ECRTD- UK

Print ISSN: ISSN 2054-6351

Online ISSN: ISSN 2054-636X

\section{THE RESULTS OF THE STUDY AND ITS DISCUSSION}

The first hypothesis: There are no significant differences on the subjective effectiveness scale between the average performance of the experimental group that was exposed to active learning strategy and the average performance of the control group in the posttest.To examine the study hypothesis, the mean and standard deviations for the scores of the students of the two groups were extracted in the post-application of the self-efficacy scale. Then, the results of the (T) test for the independent samples were extracted to reveal the significance of the differences between the averages. Table (5) shows these results.

Table No. (5) mean and standard deviations for the scores of students of the two groups in the post-application on the scale of self-efficacy and the results of the test (T) to indicate the differences between the averages.

\begin{tabular}{|l|l|l|l|l|l|}
\hline Group & $\mathrm{N}$ & mean & SD & T & sig \\
\hline Experimental & 29 & 108.55 & 14.33 & 3.45 & 0.001 \\
\cline { 1 - 3 } Control & 30 & 90.73 & 23.99 & & \\
\hline
\end{tabular}

It is noted from Table (5) that there are statistically significant differences at the level of significance $(\alpha \leq 0.05)$ on the dimensional subjective effectiveness scale, and by reference to the arithmetic averages it is observed that these differences are in favour of the experimental group, and thus reject the zero hypothesis, and accept the alternative hypothesis, which means that strategies Active learning positively affects the development of students' self-efficacy.This result can be attributed to the fact that active learning strategies have worked to strengthen students' confidence in themselves and their capabilities on the one hand and enhance confidence between them and the subject teacher on the other hand, and they have the opportunity to choose and work on their own, and reflect on their practice and thinking and express their experiences. They became interested in carrying out the duties and appointments entrusted to them, and they spent extra effort and time in accomplishing them. All of this was reflected in their sense of self-efficacy, and their enhancement. The result of this study is consistent with that of Wilke (2003). The second hypothesis: There are no fundamental differences in academic achievement in Islamic education between the average performance of the experimental group that was exposed to active learning strategy and the average performance of the control group in the post-test.

To examine the study hypothesis, the arithmetic averages and the standard deviations for the scores of the students of the two groups in the post-test achievement in the subject of Islamic education were extracted, then the results of the $(\mathrm{T})$ test were extracted to reveal the significance of the differences between the averages. Table (6) shows these results. 
Table (6) means and standard deviations for the scores of students of the two groups in the post-application to the achievement test and the results of the test (T) to indicate the differences between the averages

\begin{tabular}{|l|l|l|l|l|l|}
\hline Group & N & mean & SD & T & sig \\
\hline Experimental & 29 & 18.17 & 1.44 & 6.04 & 0.001 \\
\cline { 1 - 3 } & 30 & 14.97 & 2.51 & & \\
\hline
\end{tabular}

It is noted from Table No. (6) that there are statistically significant differences at the level of significance $(\alpha \leq 0.05)$ between the two experimental groups and the control on the post achievement test in the subject of Islamic education, and by reference to the arithmetic mean, it is noted that these differences are in favour of the experimental group. By this, we reject the zero hypothesis and accept the alternative hypothesis, which means that active learning strategies positively affect the development of students' academic achievement.

This result can be attributed to the fact that the students of the experimental group that underwent active learning were active participants in the educational-learning process, and they were given an opportunity in light of these strategies to develop positive attitudes towards learning and encourage them to explore their attitudes and values, and develop their internal motivation to motivate them to learn and facilitate their learning Bypassing practical experiences related to real problems in their lives, increasing their attention, increasing interaction within the classroom, and developing their higher-order thinking skills, all of this leads in the end to students' greater achievement of what they learn. The results of this study are consistent with the results of the studies of Taraban, R.; Box, C. \& Orhan, A. (2007) and McCarthy \& Anderson (2000).

\section{Recommendations:}

In light of the results of this study, a number of proposals can be proposed, summarized as follows:

- $\quad$ Conducting more research and studies with the aim of investigating the impact of active learning strategies at the different school and university levels of study.

- $\quad$ Encouraging teachers at the different levels of study they deal with to employ active learning strategies, because of their positive effects

\section{References}

Bandura,A.(1997).Self-efficacy: The exercise of control. New York: Free-man.

Carroll,L.\& Leander, S. (2001). Improve Motivation through the Use of Active Learning Strategies. Unpublished Master Dissertation. Saint Xavier University.

Darwaza, Afnan (2004). Basics of educational psychology. Amman: Al-Shorouq House for Publishing and Distribution.

Ghanem, Nasser (2007). The effect of a training program on organized learning. Unpublished $\mathrm{PhD}$ thesis, University of Jordan, Amman, Jordan. 
British Journal of Education

Vol.8, Issue 2, pp.52-62, February 2020

Published by ECRTD- UK

Print ISSN: ISSN 2054-6351

Online ISSN: ISSN 2054-636X

Harasim,L.et al.(1997).Learning Networks;A Field Guide to Teaching and Learning Online, M.A., Massachusetts: Institute of Technology,Cambridge.

McCarthy, J. \& Anderson, L. (2000). Active Learning Techniques versus Traditional Teaching Styles: Two Experiments from History and Political Science. Innovative Higher Education.24 (4), 279-294.

Myers, C. \& Jones, T. (1993). Promoting Active Learning Strategies for the College Classroom. San Francisco, Jossey-Bass Inc.

Paulson, D. \& Faust, J. (2006). Active Learning for the College Classroom. Available at: http:/chemistry.calstatela.edu/chem.\& Biochem./active/main.html.

Purdie, N.; Hattie, J. \& Doug, G. (1996). Student Conception of Learning \& Their Use of Self-Regulated Learning Strategies: A Cross- Cultural Comparison. Journal of educational Psychology. 88,87-100.

Scheyvens, R.; Griffin, A.; Jocoy, C.; Liu, Y. \& Bradford, M.(2008). Experimenting with Active Learning in Geography: Dispelling the Myths That Perpetuate Resistance. Journal of Geography in Higher Education.32 (1), 51-69.

Tandogan, R. \& Orhan, A. (2007). The Effects of Problem-Based Active Learning in Science Education on Students' Academic Achievement, Attitude and Concept Learning. Journal of Mathematics, Science \& Technology Education. 3(1).71-81.

Wilk, R. (2003). The Effect of Active Learning on Student Characteristics in a Humman Physiology Course for None Majors. Advances in physiology Education. 27,207223.

Wittrock,M . C . (1990). Generative Process of Comprehension. Educational Psychologist. 24(4),345-376.

Zimmerman, B.J. (2002). Becoming Self-regulated Learner: an Overview. Theory into practice. 14 (2), 65-70. 